\title{
Reduction of Serum Retinol-Binding Protein-4 Levels in Nondiabetic Obstructive Sleep Apnea Patients under Continuous Positive Airway Pressure Treatment
}

\author{
Evangelia Nena ${ }^{a}$ Paschalis Steiropoulos ${ }^{a} \quad$ Argyris Tzouvelekis $^{a}$ Venetia Tsara $^{c}$ \\ Olga Hatzizisi $^{d}$ Georgios Kyriazis $^{d}$ Marios Froudarakis ${ }^{a}$ Georgia Trakada ${ }^{a}$ \\ Nikolaos Papanas ${ }^{b}$ Demosthenes Bouros ${ }^{a}$ \\ a Department of Pneumonology, Medical School, and ${ }^{\mathrm{b}} 2$ nd Department of Internal Medicine, \\ Democritus University of Thrace, Alexandroupolis, and 'Sleep Unit, 2nd Chest Department, and \\ dImmunology Laboratory, 'George Papanikolaou' General Hospital, Thessaloniki, Greece
}

\section{Key Words}

Continuous positive airway pressure $\cdot$ Obstructive sleep apnea syndrome $\cdot$ Retinol-binding protein- $4 \cdot$ Impaired fasting glucose $\cdot$ Insulin resistance

\begin{abstract}
Background: Obstructive sleep apnea syndrome (OSAS) is associated with impaired glucose metabolism and insulin resistance. Retinol-binding protein-4 (RBP-4) is an adipokine, hypothesized to induce insulin resistance. Objectives: The aim of the study was to explore the association between serum RBP-4 levels and OSAS severity in nondiabetic, adherent to therapy OSAS patients and to investigate the role of continuous positive airway pressure (CPAP) in the alteration of RBP-4 levels. Methods: OSAS patients $(n=62)$ without comorbidities or medication use were included. Fasting RBP-4, glucose and insulin levels, $\mathrm{HbA}_{1 c}$, homeostatic model assessment of insulin resistance index and lipid profile were measured at baseline and after 6 months of CPAP use. Patients were divided into group $A$ (with fasting glucose levels $<110$ $\mathrm{mg} / \mathrm{dl}, \mathrm{n}=47$ ), and group $B$ (with impaired fasting glucose (IFG), i.e. fasting glucose levels $\geq 110 \mathrm{mg} / \mathrm{dl}, \mathrm{n}=15$ ). Results: RBP-4 levels were not associated with apnea-related indices,
\end{abstract}

anthropometric characteristics or markers of glycemic control, insulin resistance or lipid profile. In group A (but not in group $B)$, a significant reduction was observed in RBP-4 ( $p=$ $0.046), \mathrm{HbA}_{1 c}(p=0.005)$, LDL cholesterol $(p=0.034)$, and high-sensitivity C-reactive protein ( $h s-C R P, p=0.033$ ) levels after 6 months of CPAP use. Conclusions: RBP-4 levels were not correlated with sleep, anthropometric characteristics, markers of glycemic control and insulin sensitivity. OSAS patients without IFG respond well to CPAP use as evidenced by the significant reduction in RBP-4, $\mathrm{HbA}_{1 c}$ and, additionally, hs-CRP and LDL- cholesterol levels. This treatment effect is not observed in patients with IFG.

Copyright $\odot 2010$ S. Karger AG, Basel

\section{Introduction}

Obstructive sleep apnea syndrome (OSAS) is a common disorder, affecting about $4 \%$ of middle-aged men and $2 \%$ of middle-aged women [1]. It is characterized by repetitive episodes of partial or complete obstruction of the upper airway during sleep, associated with increasing respiratory effort, leading to oxyhemoglobin desaturation, sleep fragmentation, and daytime symptoms - most

\section{KARGER}

Fax +41613061234 E-Mail karger@karger.ch www.karger.com
(C) 2010 S. Karger AG, Basel

0025-7931/10/0806-0517\$26.00/0

Accessible online at:

www.karger.com/res
Evangelia Nena, $\mathrm{MD}, \mathrm{PhD}$

Department of Pneumonology

Medical School, Democritus University of Thrace

GR-68100 Alexandroupolis (Greece)

Tel. +30 255107 6105, Fax +30 255107 6106, E-Mail enena@ med.duth.gr 
commonly excessive sleepiness [2]. Accumulating evidence suggests that OSAS may be an independent risk factor for insulin resistance and the metabolic syndrome [2-4], as well as for overt type 2 diabetes [4], independently of obesity.

The treatment of choice for most cases of OSAS is continuous positive airway pressure (CPAP), which eliminates upper airway collapse during sleep, improves sleep fragmentation, daytime symptoms and quality of life [2]. CPAP also improves several biomarkers of increased cardiovascular risk $[5,6]$ and insulin sensitivity [7] in OSAS patients. Studies conducted previously in our center have demonstrated that adherence to CPAP treatment plays an important role in ameliorating the levels of markers of cardiovascular risk [6], glucose dysmetabolism [8], or inflammation [9].

Retinol-binding protein-4 (RBP-4) is an adipokine which has been shown to regulate glucose metabolism and to contribute to insulin resistance in several experimental models and human studies $[10,11]$. Increased serum RBP-4 levels have been linked with obesity, diabetes mellitus, or impaired glucose tolerance. Additionally, therapeutic interventions, such as exercise [11], or weight loss after bariatric surgery [12], have proven effective in reducing RBP-4 levels. Therefore, RBP-4 has been proposed as a marker for identifying subjects at higher risk for diabetes and cardiovascular disease and as an index for successful therapeutic interventions [13].

However, other workers have failed to show a relationship between RBP-4 levels and insulin sensitivity [14-16]. Moreover, there is only one report in Japanese subjects on the interaction between RBP- 4 and OSAS. According to this work, RBP-4 levels are significantly increased in moderate/severe OSAS patients as compared to controls, but no correlation could be established between RBP-4 and apnea-related variables [17].

Thus, the aim of the present study was to examine the possible correlation between serum RBP-4 levels and OSAS severity in nondiabetic Caucasian OSAS patients, and to explore the effect of 6-month CPAP therapy on the modification of RBP-4 levels.

\section{Methods}

\section{Patients}

This study recruited patients with newly polysomnographically diagnosed OSAS [apnea-hypopnea index (AHI) $\geq 15 / \mathrm{h}$ ] to whom CPAP treatment was initiated, and who were adherent to treatment at the 6-month follow-up. All subjects had been referred to the Sleep Laboratory of the Department of Pneumonol- ogy at the University Hospital of Alexandroupolis, Greece, and to the Sleep Unit of George Papanikolaou General Hospital, Thessaloniki, Greece, between January and June 2007, with symptoms suggestive of sleep-related breathing disorders. Subjects had not previously been examined or treated for OSAS.

Exclusion criteria at baseline were as follows: diabetes mellitus, cardiovascular or cerebrovascular disease, hypertension, liver, endocrine, inflammatory or other chronic disease, use of systemic medication, smoking and alcohol abuse. Additional exclusion criteria at follow-up were: poor adherence to CPAP use (i.e. mean CPAP use $\leq 4 \mathrm{~h} /$ night), change in body mass index (BMI) exceeding $5 \%$, and self-reported significant changes in dietary habits and/or physical activity.

The study was approved by the Ethics Committee and all participants gave their written informed consent.

Study Design

Initial Assessment

At baseline, medical history was recorded and a physical examination was performed. Anthropometrical data (age, sex, BMI, neck, waist and hip circumference) along with daytime habits, such as exercise, smoking and alcohol use, were recorded. Weight and height were measured to the nearest kilogram and centimeter, respectively, in lightly clothed subjects without shoes and BMI was calculated [BMI = weight (in kilograms)/height (in meters $)^{2}$. Neck circumference was measured at the cricothyroid level, waist circumference in the middle between the 12 th rib and the iliac crest and hip circumference at the level of the great trochander with a measuring tape. Alcohol use was assessed as the number of alcohol units consumed per week. Diabetes was defined by a fasting glycaemia above $126 \mathrm{mg} / \mathrm{dl}$ [18] and impaired fasting glucose (IFG) as fasting glucose levels $\geq 110 \mathrm{mg} / \mathrm{dl}$. Sleepiness was evaluated by the Greek version of the Epworth Sleepiness Scale [19].

\section{Polysomnography}

All subjects underwent an attended overnight polysomnography (PSG; Somnologica 3.1; Flaga; Reykjavik, Iceland or Alice-4, Respironics, Murrysville, Pa., USA) using a standard montage of electroencephalogram (EEG), electroocculogram, electromyogram and electrocardiogram signals together with pulse oximetry and airflow detected using combined oronasal thermistors. Thoracic cage and abdominal motion were recorded by inductive plethysmography. EEG recordings were manually scored according to standard criteria. Apnea was defined as complete cessation of airflow for $\geq 10 \mathrm{~s}$ and hypopnea as a $50 \%$ reduction in airflow for $\geq 10$ s, accompanied by a $\geq 4 \%$ desaturation or by an EEGrecorded arousal. AHI was defined as the total number of apneas and hypopneas per hour of electroencephalographic sleep. PSG was performed from 22.00 to $06.00 \mathrm{~h}$. Patients with pure or mainly central apneas were excluded from the study. Patients with OSAS who started CPAP treatment underwent a second sleep study for CPAP titration. Optimum CPAP pressure was defined as the pressure that abolished all respiratory events, arousals and desaturation episodes.

Follow-Up

At the 6-month follow-up, adherence to therapy was calculated by dividing the number of CPAP use hours in the device timer by application time. Blood samples were collected between 
Table 1. Baseline anthropometric and sleep characteristics of all OSAS patients included in the study, and comparison between groups $\mathrm{A}$ and $\mathrm{B}$

\begin{tabular}{|c|c|c|c|c|}
\hline & $\begin{array}{l}\text { Total } \\
(\mathrm{n}=62)\end{array}$ & $\begin{array}{l}\text { Group A: } \\
\text { no IFG }(\mathrm{n}=47)\end{array}$ & $\begin{array}{l}\text { Group B: } \\
\text { IFG }(n=15)\end{array}$ & $\mathrm{p}$ \\
\hline Age, years & $46.4 \pm 11.3$ & $45.2 \pm 11.4$ & $49.8 \pm 10.4$ & 0.165 \\
\hline $\mathrm{BMI}, \mathrm{kg} / \mathrm{m}^{2}$ & $33.9 \pm 6.9$ & $33.1 \pm 7.4$ & $36.1 \pm 5$ & 0.109 \\
\hline Neck circumference, $\mathrm{cm}$ & $43.2 \pm 3.2$ & $42.6 \pm 3$ & $45.2 \pm 3.1$ & 0.004 \\
\hline Waist circumference, $\mathrm{cm}$ & $114.5 \pm 12.9$ & $112.6 \pm 13.6$ & $120.3 \pm 8.3$ & 0.042 \\
\hline Hip circumference, $\mathrm{cm}$ & $117.9 \pm 19.2$ & $116.9 \pm 20.1$ & $121.3 \pm 16.2$ & 0.445 \\
\hline Waist-to-hip ratio & $0.979 \pm 0.081$ & $0.972 \pm 0.082$ & $1.001 \pm 0.073$ & 0.209 \\
\hline Epworth Sleepiness Scale & $11.6 \pm 5.7$ & $11.4 \pm 5.6$ & $12.3 \pm 5.8$ & 0.611 \\
\hline AHI, events/h & $57.4 \pm 27.5$ & $55.9 \pm 30$ & $62.1 \pm 17.7$ & 0.636 \\
\hline ODI, events/h & $58.5 \pm 28$ & $56.7 \pm 30.7$ & $64.1 \pm 17.3$ & 0.509 \\
\hline Average $\mathrm{SpO}_{2}, \%$ & $90.1 \pm 4.7$ & $90.3 \pm 5.1$ & $89.7 \pm 3.2$ & 0.942 \\
\hline Minimum $\mathrm{SpO}_{2}, \%$ & $72.5 \pm 9.9$ & $73.5 \pm 10.3$ & $69.2 \pm 8.1$ & 0.311 \\
\hline $\mathrm{t}<90, \% \mathrm{TST}$ & $33.3 \pm 27.7$ & $32 \pm 29.7$ & $37.6 \pm 19.7$ & 0.515 \\
\hline Heart rate, bpm & $69.4 \pm 9.1$ & $69.3 \pm 9.7$ & $69.8 \pm 7.4$ & 0.879 \\
\hline
\end{tabular}

TST $=$ Total sleep time

8 and 9 a.m. following an overnight fast from the OSAS patients who filled the inclusion criteria.

\section{Measurement of Serum RBP-4 Levels and Biochemical}

Analysis

Blood was collected between 8 and 9 a.m. following an overnight fast and serum was frozen in aliquots at $-80^{\circ} \mathrm{C}$ immediately after centrifugation $\left(4^{\circ} \mathrm{C}, 1,600 \mathrm{~g}\right.$ for $\left.15 \mathrm{~min}\right)$. Serum RBP-4 levels were measured by an enzyme immunoassay (Phoenix Pharmaceuticals, Belmont, Calif., USA), and intra- and interassay variability were $<5 \%$ and $<14 \%$, respectively. No cross-reactivity was found with human insulin, ghrelin, motilin, apelin, visfatin, leptin or other relevant molecules. The sensitivity of the assay was $215.5 \mu \mathrm{g} / \mathrm{ml}$. All samples were run in duplicate, and mean values were used for subsequent analysis. Total, HDL and LDL cholesterol and triglyceride levels were measured by enzymatic colorimetric methods while glucose was measured by an enzymatic method (Olympus AU640; Hamburg, Germany). Fasting insulin was measured by a electrochemiluminescence immunoassay (DPC Immulite 2000) and high-sensitivity C-reactive protein (hs-CRP) was measured by a nephelometric method in an image analyzer (Beckmann Coulter, Calif., USA). The homeostatic model assessment of insulin resistance (HOMA-IR) index was used to assess each subject's insulin resistance. The HOMA-IR was calculated from fasting plasma glucose and insulin values measured in a single sample according to the formula: insulin $(\mathrm{mU} / \mathrm{l}) \times$ glucose $(\mathrm{mmol} / \mathrm{l}) / 22.5[20]$.

\section{Statistical Analysis}

Analysis was performed using SPSS v.15.0 (SPSS Inc., Chicago, Ill., USA). All continuous variables were checked for normality (Kolmogorov-Smirnov test). Descriptive results for continuous variables are expressed as means $\pm \mathrm{SD}$. Linear regression analysis was performed after controlling for BMI as a confounding factor with four different models, each comprising anthropometric, sleep, or metabolic parameters. Paired-sample t test (for normally distributed variables) and the Wilcoxon signed rank test (for abnormally distributed variables) were used to assess the difference of means before and after CPAP treatment. Baseline differences between patients with and without IFG were examined with the independent-sample t test or the Mann-Whitney test, depending on the normality of data distribution. The reported $\mathrm{p}$ values are two-tailed. Significance was defined at the 5\% level $(\mathrm{p}<0.05)$.

\section{Results}

Initially, 358 OSAS patients from both centers consented to participate in the study. These had been examined by PSG and were initiated on CPAP treatment. Of these, 237 were excluded from this study because of comorbidities or smoking. Therefore, 121 OSAS patients were included. At the 6-month follow-up, a further 59 patients were rejected due to poor adherence to CPAP (mean CPAP use $<4 \mathrm{~h} /$ night, $\mathrm{n}=45$ ), significant loss of body weight $(\mathrm{n}=5)$, surgical treatment of OSAS $(\mathrm{n}=3)$, or loss to follow-up $(\mathrm{n}=6)$. Thus, 62 patients $(85.5 \%$ males) were finally included.

Baseline anthropometric and sleep characteristics of these 62 OSAS patients are presented in table 1. Patients had moderate and severe OSAS with baseline AHI ranging between $15.3 / \mathrm{h}$ and $123.3 / \mathrm{h}$, and scores on the Epworth Sleepiness Scale ranging between 2 and 24 and showed good adherence to treatment (mean CPAP use $4.72 \pm 0.66 \mathrm{~h} / \mathrm{night})$. Despite the fact that all 62 patients 
Table 2. Baseline levels of glycemic and lipidemic control markers and of hs-CRP levels in all OSAS patients included in the study, and comparison between groups A and B

\begin{tabular}{lcccc}
\hline & $\begin{array}{l}\text { Total } \\
(\mathrm{n}=62)\end{array}$ & $\begin{array}{l}\text { Group A: } \\
\text { no IFG }(\mathrm{n}=47)\end{array}$ & $\begin{array}{l}\text { Group B: } \\
\text { IFG (n=15) }\end{array}$ & $\mathrm{p}$ \\
\hline RBP-4, $\mu \mathrm{g} / \mathrm{ml}$ & $53.4 \pm 17.1$ & $55.5 \pm 17.4$ & $48.5 \pm 15.6$ & 0.169 \\
Fasting glucose, mg/dl & $99.9 \pm 13.1$ & $94.1 \pm 8.9$ & $117.9 \pm 5$ & 0.000 \\
HbA,$\%$ & $5.56 \pm 0.72$ & $5.35 \pm 0.34$ & $6.2 \pm 1.08$ & 0.003 \\
Fasting insulin, $\mu \mathrm{IU} / \mathrm{ml}$ & $14.8 \pm 11.5$ & $12.4 \pm 8.9$ & $21.7 \pm 15.3$ & 0.002 \\
HOMA-IR & $3.7 \pm 3.3$ & $2.8 \pm 2$ & $6.3 \pm 4.6$ & 0.006 \\
Total cholesterol, mg/dl & $240.9 \pm 45.1$ & $242.4 \pm 50.6$ & $236.3 \pm 20.2$ & 0.508 \\
HDL cholesterol, mg/dl & $41.7 \pm 9.2$ & $43 \pm 9.2$ & $37.4 \pm 7.7$ & 0.038 \\
LDL cholesterol, mg/dl & $155.5 \pm 45.6$ & $160.5 \pm 47.4$ & $139.9 \pm 36.2$ & 0.127 \\
Triglycerides, mg/dl & $199.9 \pm 154.2$ & $176.6 \pm 151.3$ & $266.8 \pm 146.8$ & 0.021 \\
hs-CRP, mg/dl & $0.579 \pm 0.497$ & $0.6 \pm 0.53$ & $0.52 \pm 0.39$ & 0.598 \\
\hline
\end{tabular}

were normoglycemic, in 15 of them (24.2\%) IFG was detected. Patients were divided into two groups according to the presence of IFG: group A (without IFG, mean fasting glucose $94.1 \pm 8.9 \mathrm{mg} / \mathrm{dl}$ ) and group B (with IFG, mean fasting glucose $117.9 \pm 5 \mathrm{mg} / \mathrm{dl}$ ) and comparisons were performed.

No differences had been detected at baseline examination, between groups A and B in terms of age $(\mathrm{p}=0.162)$, BMI $(p=0.135)$, waist-to-hip ratio $(\mathrm{p}=0.209)$, AHI $(\mathrm{p}=$ $0.636)$, nocturnal oxygen desaturations (ODI, $\mathrm{p}=0.509$ ), average and minimum oxygen saturation on pulse oximetry $\left(\mathrm{SpO}_{2}, \mathrm{p}=0.942\right.$ and $\mathrm{p}=0.311$, respectively). As expected, baseline along with differences in $\mathrm{HbA}_{1 \mathrm{c}}$ levels $(\mathrm{p}=0.006)$, insulin $(\mathrm{p}=0.005)$ and HOMA-IR $(\mathrm{p}=$ 0.009). Although in patients with IFG lower baseline RBP-4 levels were detected, the difference between groups did not reach statistical significance $(55.5 \pm 17.4$ $\mu \mathrm{g} / \mathrm{ml}$ in group A vs. $48.5 \pm 15.6 \mu \mathrm{g} / \mathrm{ml}$ in group $\mathrm{B}, \mathrm{p}=$ 0.169). Additionally, the HDL-cholesterol levels of the IFG group were significantly lower than those of the nonIFG group, while the levels of triglycerides were found to be higher. Glycemic and lipidemic profiles of all OSAS patients and of each group separately are presented in table 2 .

Regression analysis showed that neither indices of OSAS severity, nor anthropometric and metabolic characteristics could predict RBP-4 levels. Specifically, the potential correlation between RBP-4 levels and four different models comprising anthropometric, sleep, or metabolic characteristics, independently of BMI was explored. In the first model, $\mathrm{AHI}$, average $\mathrm{SpO}_{2}$, and levels of $\mathrm{HbA}_{1 \mathrm{c}}$ were included. In the second one, the levels of
Table 3. Results of regression analysis using RBP-4 levels as the dependent variable and four different models comprising sleep, anthropometric, or metabolic characteristics

\begin{tabular}{|c|c|c|c|c|}
\hline & $\beta$ & Significance & $\mathrm{F}$ & $\mathrm{p}$ \\
\hline BMI & -0.226 & 0.077 & 3.241 & 0.077 \\
\hline AHI & -0.324 & 0.054 & & \\
\hline Average $\mathrm{SpO}_{2}$ & -0.050 & 0.787 & 2.187 & 0.082 \\
\hline $\mathrm{HbA}_{1 \mathrm{c}}$ & 0.016 & 0.905 & & \\
\hline Fasting glucose & -0.053 & 0.303 & & \\
\hline hs-CRP & -0.234 & 0.681 & 1.672 & 0.169 \\
\hline Minimum $\mathrm{SpO}_{2}$ & 0.154 & 0.121 & & \\
\hline $\mathrm{t}<90$ & -0.196 & 0.186 & & \\
\hline Total cholesterol & -0.040 & 0.766 & 1.282 & 0.288 \\
\hline HOMA-IR & 0.001 & 0.993 & & \\
\hline Fasting insulin & -0.089 & 0.509 & & \\
\hline Neck circumference & 0.234 & 0.087 & 1.763 & 0.149 \\
\hline Waist-to-hip ratio & -0.125 & 0.334 & & \\
\hline
\end{tabular}

fasting glucose and hs-CRP, as well as minimum $\mathrm{SpO}_{2}$ were included. In the third and fourth model, percentage of sleep time with $\mathrm{SpO}_{2}<90 \%$, total cholesterol levels, HOMA-IR and fasting insulin, neck circumference waistto-hip ratio were included. As demonstrated in table 3, none of the parameters included in any of the four models was predictive of RBP-4 values.

At the 6-month follow-up, blood samples were recollected. A decreasing trend was observed in RBP-4 levels (from $53.4 \pm 17.1$ to $50.1 \pm 16 \mu \mathrm{g} / \mathrm{ml}$ ) in general. This 
Table 4. Comparison of baseline and follow-up levels of glycemic and lipidemic control markers and of hs-CRP levels in groups A and B

\begin{tabular}{|c|c|c|c|c|c|c|}
\hline & \multicolumn{3}{|c|}{ Group A: no IFG $(\mathrm{n}=47)$} & \multicolumn{3}{|c|}{ Group B: IFG $(\mathrm{n}=15)$} \\
\hline & baseline & follow-up & $\mathrm{p}$ & baseline & follow-up & $\mathrm{p}$ \\
\hline BMI, kg/m² & $33.1 \pm 7.3$ & $33.2 \pm 7.1$ & 0.419 & $36.4 \pm 5.1$ & $36.4 \pm 5.1$ & 0.970 \\
\hline $\mathrm{RBP}-4, \mu \mathrm{g} / \mathrm{ml}$ & $55.5 \pm 17.4$ & $50.5 \pm 16$ & 0.046 & $48.5 \pm 15.6$ & $48.8 \pm 16.9$ & 0.938 \\
\hline Fasting glucose, $\mathrm{mg} / \mathrm{dl}$ & $94.1 \pm 8.9$ & $96.3 \pm 9.7$ & 0.241 & $117.9 \pm 5$ & $123.8 \pm 16.3$ & 0.258 \\
\hline $\mathrm{HbA}_{1 \mathrm{c}}, \%$ & $5.35 \pm 0.34$ & $5.26 \pm 0.39$ & 0.005 & $6.2 \pm 1.08$ & $6.03 \pm 1.02$ & 0.242 \\
\hline Fasting insulin, $\mu \mathrm{IU} / \mathrm{ml}$ & $12.4 \pm 8.9$ & $11.5 \pm 6.3$ & 0.474 & $21.7 \pm 15.3$ & $23.2 \pm 22.2$ & 0.393 \\
\hline HOMA-IR & $2.8 \pm 2$ & $2.7 \pm 1.5$ & 0.866 & $6.3 \pm 4.6$ & $7.4 \pm 8.2$ & 0.501 \\
\hline Total cholesterol, mg/dl & $242.4 \pm 50.6$ & $233 \pm 42.4$ & 0.073 & $236.3 \pm 20.2$ & $233.8 \pm 27.2$ & 0.699 \\
\hline HDL cholesterol, mg/dl & $43 \pm 9.2$ & $44 \pm 9.8$ & 0.287 & $37.4 \pm 7.7$ & $39.5 \pm 10.1$ & 0.218 \\
\hline LDL cholesterol, mg/dl & $160.5 \pm 47.4$ & $149.6 \pm 37.2$ & 0.034 & $139.9 \pm 36.2$ & $142.5 \pm 35.1$ & 0.746 \\
\hline Triglycerides, mg/dl & $176.6 \pm 151.3$ & $171 \pm 102$ & 0.870 & $266.8 \pm 146.8$ & $257.4 \pm 156.1$ & 0.501 \\
\hline hs-CRP, mg/dl & $0.6 \pm 0.53$ & $0.53 \pm 0.42$ & 0.033 & $0.52 \pm 0.39$ & $0.53 \pm 0.46$ & 0.910 \\
\hline
\end{tabular}

reduction was significant in group $\mathrm{A}(\mathrm{p}=0.046)$, but not in group $B(p=0.938)$. In addition, apart from $\mathrm{HbA}_{1 \mathrm{c}}$ levels $(\mathrm{p}=0.005)$, a statistically significant reduction was also observed in the levels of LDL cholesterol $(\mathrm{p}=0.034)$ and hs-CRP ( $\mathrm{p}=0.033)$, as well as a decreasing trend in the levels of fasting insulin and HOMA-IR, exclusively in group A patients. Changes of metabolic parameters in the two groups after 6 months of CPAP treatment are summarized in table 4 .

\section{Discussion}

To the best of our knowledge, this is the first study evaluating the role of OSAS severity and the effect of CPAP treatment on RBP-4 levels in nondiabetic Caucasians. Our main finding is that CPAP treatment can effectively reduce RBP-4 levels in this setting, as long as fasting glucose levels are not impaired. By contrast, CPAP is ineffective in reducing these levels in patients with IFG. This novel observation suggests that the beneficial effect of CPAP on RBP-4 is dependent on the presence or absence of glucose dysmetabolism. It is plausible that the effect of CPAP is not strong enough in the presence of IFG to reduce RBP-4 levels. The reason for this diminution of the effect of CPAP remains unclear, and a final answer can only be provided if the interaction between OSAS and RBP-4 is further elucidated.

It is also noteworthy that the reduction in RBP-4 levels in group $\mathrm{A}$ was accompanied by a significant reduction in $\mathrm{HbA}_{1 \mathrm{c}}$, LDL cholesterol and hs-CRP, and a modest, nonsignificant reduction in fasting insulin, HOMA-IR and total cholesterol. Again, no such effects were noticeable in group B. Our results are in line with Tschoner et al. [12], who demonstrated that another therapeutic intervention (i.e. weight loss after surgery) resulted in a greater reduction in RBP-4 levels in patients with no metabolic syndrome, whereas the reduction observed in patients with metabolic syndrome was smaller. One could postulate that the observed reduction in RBP-4 levels depicts the amelioration of cardiovascular risk after compliance with CPAP treatment in non-IFG patients since RBP- 4 has been proposed as a marker for cardiovascular risk, as well as diabetes mellitus [13].

Interestingly, and in keeping with Makino et al. [17], no correlation was established between RBP-4 levels and apnea-related characteristics, supporting the hypothesis that the increase in RBP-4 levels among OSAS patients is multifactorial and certainly not directly attributable to the severity of OSAS per se. In contrast to previous works $[12,13,17]$, in our study no correlation was revealed between RBP-4 levels and obesity (as indicated by BMI) or central obesity (as indicated by waist-to-hip ratio), tempting us to consider whether an anti-inflammatory action could, at least in part, explain the observed effects. Nonetheless, there are not enough data to answer this question in the affirmative.

The association between OSAS and secretion of adipokines has been a subject of scientific research over the last years [20-22]. RBP-4, which is also secreted by adipocytes and the liver, has been linked with impaired glucose metabolism and insulin resistance in several experimental models $[14,15]$. It has been suggested that RBP-4 modulates insulin sensitivity both in muscles and in the liver 
$[14,15]$. A strong association between RBP-4 levels and the risk of metabolic syndrome has been reported as well [24]. Serum RBP-4 levels have been found to correlate with the severity of insulin resistance $[10,11]$. A more recent study has demonstrated that the reduction in visceral fat in 52 nondiabetic subjects decreased serum levels of RBP- 4 by $25.5 \%$ [25].

In the present work, no association was observed between RBP-4 levels and markers of insulin resistance. This finding is in agreement with previous research [14, $16,26]$. Yang et al. [14] reported no difference in RBP-4 levels between obese nondiabetic and obese diabetic subjects despite the increased insulin resistance of the latter. Another work [26] showed that RBP-4 gene expression in nondiabetic subjects is significantly related with inflammatory markers, but not with insulin resistance. Similarly, Silha et al. [16] found no association between serum levels of RBP- 4 and markers of insulin resistance in women. These observations, along with our findings, suggest that RBP-4 levels may depend on mechanisms that involve inflammation, hyperglycemia and fat accumulation rather than insulin resistance. It has also been reported that genetic variations may be of significance, with a role for a specific RBP-4 haplotype that possibly affects RBP-4 production, leading to insulin resistance and type 2 diabetes [27].

In conclusion, we have shown a beneficial effect of CPAP on serum RBP-4 levels in OSAS patients without IFG. This new finding indicates that the favorable effect of CPAP treatment on RBP-4 is dependent on the presence or absence of glucose dysmetabolism. Interestingly, no correlation appears to exist between RBP-4 levels and apnea-related characteristics. Additional work is, therefore, needed to clarify the interplay between OSAS and RBP-4 levels as well as the mechanisms that upregulate RBP-4 production. Future studies also need to investigate the potential utility of this adipokine as a marker of response to treatment.

\section{References}

1 Young T, Palta M, Dempsey J, Skatrud J, Weber S, Badr S: The occurrence of sleep-disordered breathing among middle-aged adults. N Engl J Med 1993;328:1230-1235.

2 McNicholas WT, Bonsigore MR: Sleep apnoea as an independent risk factor for cardiovascular disease: current evidence, basic mechanisms and research priorities. Eur Respir J 2007;29:156-178.

-3 Vgontzas AN, Bixler EO, Chrousos GP: Sleep apnea is a manifestation of the metabolic syndrome. Sleep Med Rev 2005;9:211-224.

4 Punjabi NM, Sorkin JD, Katzel LI, Goldberg AP, Schwartz AR, Smith PL: Sleep-disordered breathing and insulin resistance in middle-aged and overweight men. Am J Respir Crit Care Med 2002;165:677-682.

$\checkmark 5$ Robinson GV, Pepperell JC, Segal HC, Davies RJ, Stradling JR: Circulating cardiovascular risk factors in obstructive sleep apnoea: data from randomised controlled trials. Thorax 2004;59:777-782.

-6 Steiropoulos P, Tsara V, Nena E, Fitili C, Kataropoulou M, Froudarakis M, Christaki P, Bouros D: Effect of continuous positive airway pressure treatment on serum cardiovascular risk factors in patients with obstructive sleep apnea-hypopnea syndrome. Chest 2007;132:843-851.
7 Harsch IA, Schahin SP, Radespiel-Troger M, Weintz O, Jahreiss H, Fuchs FS, Wiest GH, Hahn EG, Lohmann T, Konturek PC, Ficker $\mathrm{JH}$ : Continuous positive airway pressure treatment rapidly improves insulin sensitivity in patients with obstructive sleep apnea syndrome. Am J Respir Crit Care Med 2004; 169:156-162.

-8 Steiropoulos P, Papanas N, Nena E, Tsara V, Fitili C, Tzouvelekis A, Christaki P, Maltezos E, Bouros D: Markers of glycemic control and insulin resistance in non-diabetic patients with obstructive sleep apnea hypopnea syndrome: does adherence to CPAP treatment improve glycemic control? Sleep Med 2009;10:887-891.

$\checkmark 9$ Steiropoulos P, Kotsianidis I, Nena E, Tsara V, Gounari E, Hatzizisi O, Kyriazis G, Christaki P, Froudarakis M, Bouros D: Long-term effect of continuous positive airway pressure therapy on inflammation markers of patients with obstructive sleep apnea syndrome. Sleep 2009;32:537-543.

10 Cho YM, Youn BS, Lee H, Lee N, Min SS, Kwak SH, Lee HK, Park KS: Plasma retinolbinding protein-4 concentrations are elevated in human subjects with impaired glucose tolerance and type 2 diabetes. Diabetes Care 2006;29:2457-2461.

-11 Graham TE, Yang Q, Bluher M, Hammarstedt A, Ciaraldi TP, Henry RR, Wason CJ, Oberbach A, Jansson PA, Smith U, Kahn BB: Retinol-binding protein 4 and insulin resistance in lean, obese, and diabetic subjects. N Engl J Med 2006;354:2552-2563.
12 Tschoner A, Sturm W, Engl J, Kaser S, Laimer M, Laimer E, Weiss H, Patsch JR, Ebenbichler CF: Retinol-binding protein 4, visceral fat, and the metabolic syndrome: effects of weight loss. Obesity 2008;16:24392444.

13 Kloting N, Graham TE, Berndt J, Kralisch S, Kovac s P, Wason CJ, Fasshauer M, Schon MR, Stumvoll M, Bluher M, Kahn BB: Serum retinol binding protein is more highly expressed in visceral than in subcutaneous adipose tissue and is a marker of intra-abdominal fat mass. Cell Metab 2007;6:79-87.

14 Yang Q, Graham TE, Mody N, Preitner F, Peroni OD, Zabolotny JM, Kotani K, Quadro L, Kahn BB: Serum retinol binding protein 4 contributes to insulin resistance in obesity and type 2 diabetes. Nature 2005;436:356362 .

15 Yagmur E, Weiskirchen R, Gressner AM, Trautwein C, Tacke F: Insulin resistance in liver cirrhosis is not associated with circulating retinol-binding protein 4 . Diabetes Care 2007;30:1168-1172.

16 Silha JV, Nyomba BL, Leslie WD, Murphy LJ: Ethnicity, insulin resistance, and inflammatory adipokines in women at high and low risk for vascular disease. Diabetes Care 2007; 30:286-291. 
-17 Makino S, Fujiwara M, Suzukawa K, Handa H, Fujie T, Ohtaka Y, Komatsu Y, Aoki Y, Maruyama H, Terada Y, Hashimoto K, Sugimoto T: Visceral obesity is associated with the metabolic syndrome and elevated plasma retinol binding protein-4 level in obstructive sleep apnea syndrome. Horm Metab Res 2009;41:221-226.

$\checkmark 18$ Report of the Expert Committee on the Diagnosis and Classification of Diabetes Mellitus. Diabetes Care 1997;20:1183-1197.

- 19 Tsara V, Serasli E, Amfilochiou A, Constantinidis T, Christaki P: Greek version of the Epworth Sleepiness Scale. Sleep Breath 2004; 8:91-95.

20 Matthews DR, Hosker JP, Rudenski AS, Naylor BA, Treacher DF, Turner RC: Homeostasis model assessment: insulin resistance and beta-cell function from fasting plasma glucose and insulin concentrations in man. Diabetologia 1985;28:412-419.
21 Zhang XL, Yin KS, Wang H, Su S: Serum adiponectin levels in adult male patients with obstructive sleep apnea hypopnea syndrome. Respiration 2006;73:73-77.

22 Yamamoto Y, Fujiuchi S, Hiramatsu M, Nishigaki Y, Takeda A, Fujita Y, Yamazaki Y: Resistin is closely related to systemic inflammation in obstructive sleep apnea. Respiration 2008;76:377-385.

23 Trakada G, Steiropoulos P, Nena E, Gkioka T, Kouliatsis G, Pataka A, Sotiriou I, Anevlavis S, Papanas N, Bouros D: Plasma visfatin levels in severe obstructive sleep apnea-hypopnea syndrome. Sleep Breath 2009;13. 349-355.

24 Qi Q, Yu Z, Ye X, Zhao F, Huang P, Hu FB, Franco OH, Wang J, Li H, Liu Y, Lin X: Elevated retinol-binding protein 4 levels are associated with metabolic syndrome in Chinese people. J Clin Endocrinol Metab 2007; 92:4827-4834.
25 Lee JW, Lee HR, Shim JY, Im JA, Lee DC: Abdominal visceral fat reduction is associated with favorable changes of serum retinol binding protein-4 in nondiabetic subjects. Endocr J 2008;55:811-818.

26 Yao-Borengasser A, Varma V, Bodles AM, Rasouli N, Phanavanh B, Lee MJ, Starks T, Kern LM, Spencer HJ, 3rd, Rashidi AA, McGehee RE Jr, Fried SK, Kern PA: Retinol binding protein 4 expression in humans: relationship to insulin resistance, inflammation, and response to pioglitazone. J Clin Endocrinol Metab 2007;92:2590-2597.

27 Kovacs P, Geyer M, Berndt J, Kloting N, Graham TE, Bottcher Y, Enigk B, Tonjes A, Schleinitz D, Schon MR, Kahn BB, Bluher M, Stumvoll M: Effects of genetic variation in the human retinol binding protein- 4 gene (RBP4) on insulin resistance and fat depotspecific mRNA expression. Diabetes 2007; 56:3095-3100. 